\title{
Petri Nets and Pseudo-Bond Graphs for a Nuclear Reactor Primary Coolant System
}

\author{
Mark James Wootton \\ Faculty of Engineering, University of Nottingham, United Kingdom.E-mail: mark.wootton@nottingham.ac.uk \\ John Andrews \\ Faculty of Engineering, University of Nottingham, United Kingdom. E-mail: john.andrews@nottingham.ac.uk
}

Adam L. Lloyd

Dept. of Mathematical Sciences, Loughborough University, United Kingdom. E-mail: a.lloyd5@lboro.ac.uk

Roger Smith

Dept. of Mathematical Sciences, Loughborough University, United Kingdom. E-mail: r.smith@lboro.ac.uk

A. John Arul

Reactor Engineering Group, Indira Gandhi Centre for Atomic Research, India. E-mail: arul@igcar.gov.in

Gopika Vinod

Reactor Safety Division, Bhabha Atomic Research Centre, India. E-mail: vgopika@barc.gov.in

Shri Hari Prasad

Reactor Safety Division, Bhabha Atomic Research Centre, India.E-mail: hari_m@barc.gov.in

Vipul Garg

Reactor Safety Division, Bhabha Atomic Research Centre, India. E-mail: vipulgarg@barc.gov.in

In this paper we demonstrate the application of timed Petri Net methodology to the frequency of initiating faults in the coolant circulation system of a fictional nuclear reactor design. A second model is presented where the Petri Net is coupled with a Bond Graph representation of reactor thermodynamics, and distributions of temperatures reached by core coolant and fuel cladding during component failures is produced.

Keywords: Risk and Reliability Engineering, Nuclear Power Plants, Petri Net Modeling, Bond Graphs Modeling, Coupled PN-BG Modeling, Nuclear Reactor Coolant Circlation.

\section{Introduction}

Half of the world's operating nuclear reactors came into service between 1970 and 1985 (IAEA 2019), consequently, there are many plants still in service beyond their originally intended lifespans. When these reactors were designed, the methods available to perform their risk assessment were Fault Tree (Rasmussen, 1975) and Event Tree (Andrews and Moss 1993) analysis. However, we make use of Petri Net modeling (Petri, 1962), see figure 1. which allows one to capture any feature found in those methodologies, while also providing an easy and flexible means to represent the maintenance, repair, and aging of components. These probabilistic methodologies implicitly requires one to make assumptions about the ongoing physical conditions in the system being consid- ered. Therefore we also construct a hybrid model incorporating the Bond Graph methodology to capture the evolution of reactor core temperatures following faults arising in the primary coolant.

\section{System Description}

A demonstration system, shown schematically in figure 2, is used in this work, whose description is typical of advanced thermal reactor designs. Coolant enters the core through an inlet header and is circulated through 450 coolant channels, each containing a fuel rod clad in zircalloy-2 (Whitmarsh, 1962). On leaving the reactor, the fluid is divided into four steam separators, which extract steam to be directed to the turbine building. After condensation, feed pumps transfer coolant back to the steam separators in liquid form, from

Proceedings of the 29th European Safety and Reliability Conference.

Edited by Michael Beer and Enrico Zio

Copyright $(\odot 2019$ by ESREL2019 Organizers. Published by Research Publishing, Singapore

ISBN: 981-973-0000-00-0 :: doi: 10.3850/981-973-0000-00-0_MarkWoottonESREL 
which it can flow back into the core. When a controlled shutdown is required, a valve is shut on the pipe running to the turbine. This directs coolant on an alternative path into a set of eight shutdown condensers which sit in a large tank of water serving as a heat sink. The valve is serviced on a five year cycle. When the reactor shuts down, the isolation system is intended to provide decay removal for 40 days. In the event of loss of coolant pressure, four pressure accumulators sit ready to deliver high pressure emergency coolant, before transitioning to gravity fed low pressure injection from the aforementioned tank.

The Petri Net model considers the sequence of events leading to a coolant fault initiating event, which can arise from either coolant loss from pipe

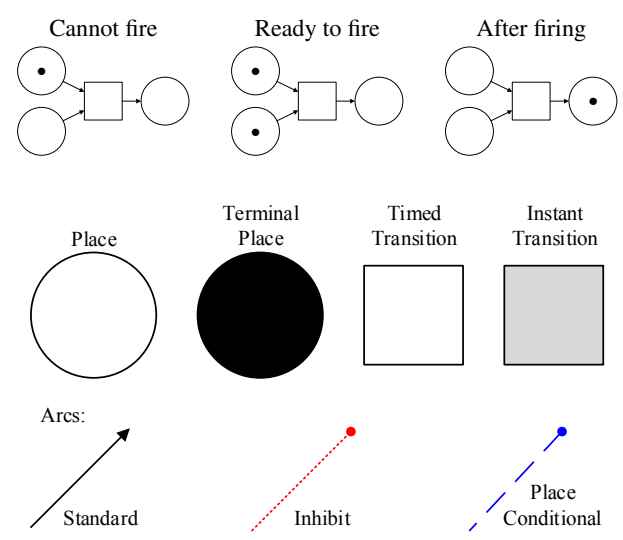

Fig. 1. An illustration of the basic Petri Net firing rule and key to objects used in depictions of Petri Nets in this work. Places hold tokens which are given and taken by transitions when the latter's arc weights are met. If a token is placed on one the black terminal places, the simulation ends. Once a transition's firing conditions are met, it may either fire instantaneously (gray fill) or after a duration selected from a probability distribution (white fill). Arcs have a weight of 1 , unless labeled otherwise.

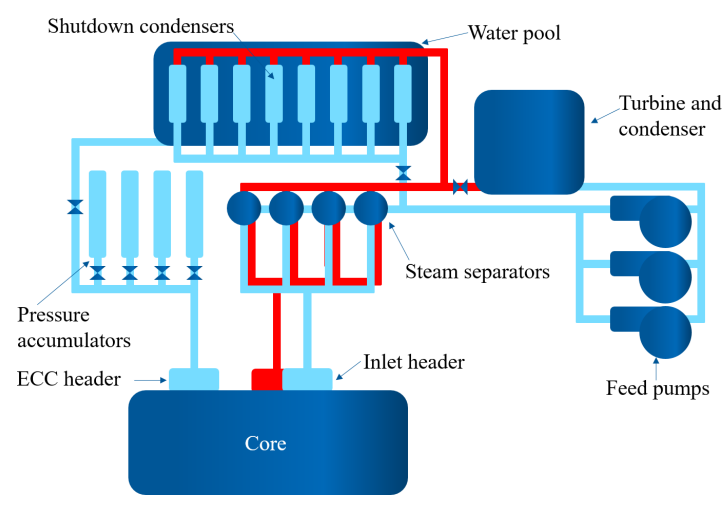

Fig. 2. Reactor core coolant circulation system schematic or steam separators, or from a critical number of concurrent feed pump failures. The system should be able to continue providing adequate coolant to the core with only two steam separators functional. If a steam separator circuit fails, a controlled shutdown is scheduled for six months time, and if a second should fail in that time, the system is shutdown immediately. Similarly the system requires that two feed pumps be running to maintain sufficient coolant, with the third standing by in case of failure, providing the necessary pumping capacity while repairs are made.

\section{Petri Net Modeling}

The Petri Net model for core coolant fault initiating events is found figure 3 . Faults occurring between the turbine isolation valve and the return of coolant to the steam separators will result in an attempt to shutdown the reactor via the shutdown condensers. As this process still relies on the circulation of coolant through the steam separators, any fault in this part of the system necessitates immediate invocation of the pressure accumulators. Thus the two outcomes that are considered are the completion of the 40 day decay heat removal period, and the occurrence of an event that mandates the initiation of the emergency injection process, faults in the shutdown condenser and emergency injection systems themselves being excluded from the model at this stage. For the parameterization of timed transitions, refer to table 1 .

A total of $2.6268 \times 10^{9}$ hours were simulated across $10^{5}$ iterations of the Petri Net, giving a mean simulated duration of 3.00 years, with a median of 2.26 years. No simulations reached the limit of 100 years. A initiating event occurred in $0.85 \%$ of the simulations, with the remainder safely completing an shutdown condenser shutdown period; these simulations respectively having mean durations of 3.28 and 2.99 years. These results give a coolant initiating fault frequency of $2.84 \times 10^{-8}$ per operational reactor year.

\section{Thermofluidics}

\subsection{Bond Graph methodology}

The Bond Graph methodology (Paynter, 1961), uses the concept of the dynamical analogy to model the transfer of power through a system comprised of varying energy domains. The elements of the system, see table 2, are connected by a network of bonds, rendered on diagrams by the symbol, $\rightarrow$, whose harpoon arrowhead denotes positive directionality. These carry an "effort" variable and a "flow" variable, the product of which gives the power moving through the bond. Effort and flow are directed at junctions and transformers, where the $\mathbf{0}$-junction splits flow and enforces equal efforts over its bonds, the 1junction splits effort and enforces equal flows, and 


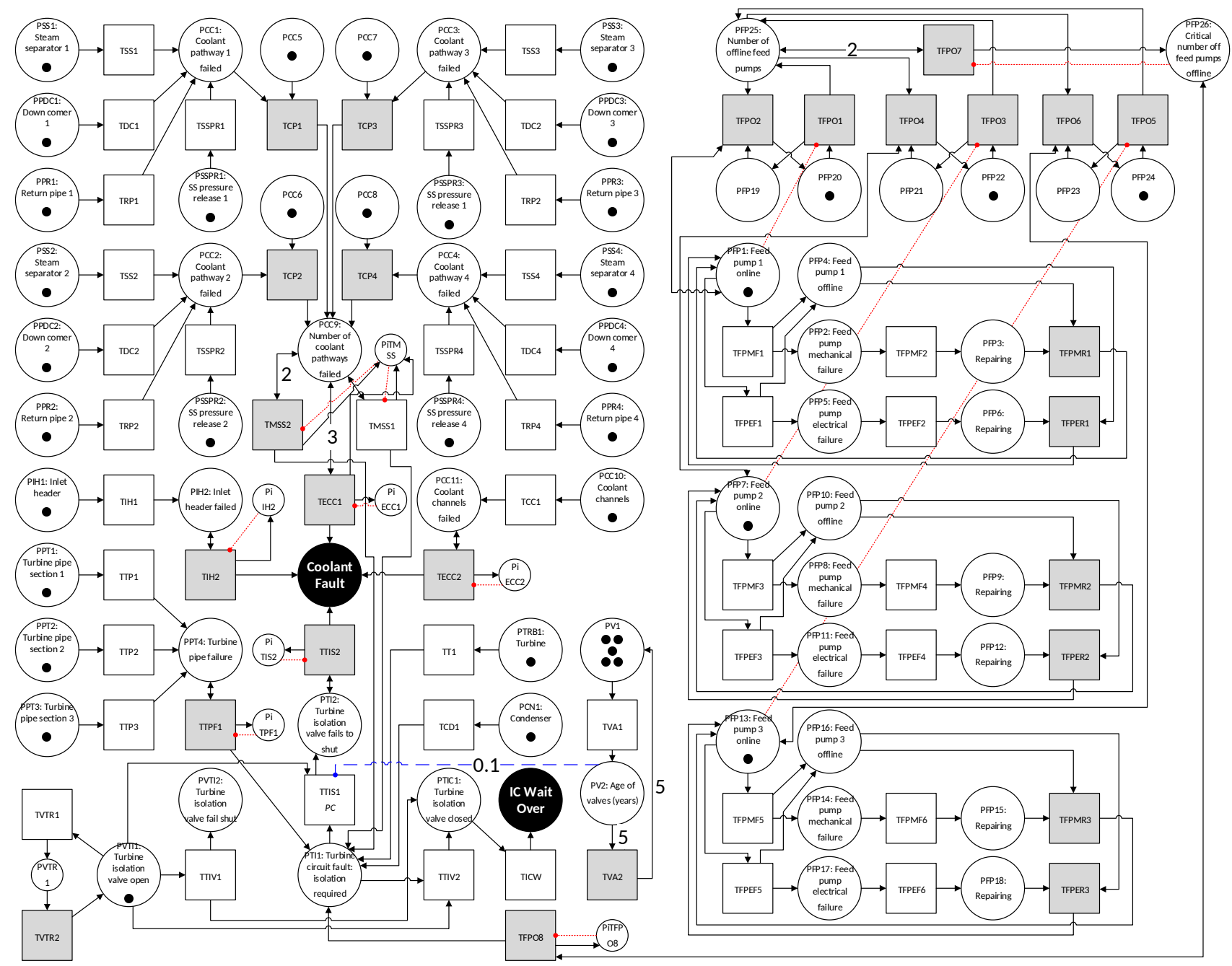

Fig. 3. Perti Net model of core coolant circulation initiating faults. The left-hand-side of the Petri Net models valve faults, and pipe and steam separator ruptures, while the right tracks the status and repairs of the feed pumps. See table 1 for transition parameters.

the transformer (TF) takes in effort and flow and outputs them multiplied by a constant. Once a representation of the system in Bond Graph form is realized, the set of simultaneous differential equations implied is solved to execute a simulation, in the case of this work, that is achieved in the Modelica language (Fritzson and Engelson, 1998), with use of the BondLib package (Cellier and Angela Nebot, 2005), and the Python interface provided by JModelica (Modelon AB., 2018).

For the physical model in this work, we are concerned with the transfer of thermal energy by the motion of fluid, i.e. advection, and therefore our Bond Graphs contain fluid domain and thermal domain concepts (Karnopp, 1978). However, the most convenient notation for the latter is to take temperature as the effort concept, and the enthalpy transfer rate as the flow concept. While the methodology for executing the bond graph does not change, this breaks the rule that the product of a bond's effort and flow should have the dimensionality of power, thus the thermal model is referred to a pseudo-Bond Graph. Also, the transfer of thermal energy is directly coupled to the motion of coolant; consequently, we introduce three additional elements: the pipe resistor, the heat transfer transformer, and the dual domain capacitor, the governing formulae of which are found in equations (1) to (3). A pipe resistor is always paired with a heat transfer transformer; the mass flow through the pipe resistor is used dynamically to control the heat transfer transformer's conversion value, and thus the enthalpy flow that accompanies the given motion of coolant. The 
Table 1. Timed transition parameters for Petri Net seen in figures 3 and 6 given in hours where applicable. The Weibull distribution is governed by a shape pameters, $\beta$ and a scale parameter, $\eta$, which for a mean time to failure, $\langle t\rangle$, is given by $\eta=\langle t\rangle / \Gamma\left(\beta^{-1}+1\right)$, where $\Gamma(x)$ is the Gamma function. "Delay" indicates a fix duration of length, $a$, "uniform" indicates a uniform probability density over in $(0, u]$. Data sourced from Hubble and Miller (1978); Smith (1981); IAEA (1988); GRS (1990); Eide et al. (1990); Eide and Calley (1993); Cadwallader (1998); Barringer \& Associates, Inc (2010), the US Nuclear Regulatory Commission, India's Atomic Energy Regulatory Board, and expert opinions. Please note that these figures are to be taken as representative values for a fictional reactor.

\begin{tabular}{llllll}
\hline Transition & Distribution & Parameter(s) & Transition & Distribution & Parameter(s) \\
\hline TVA1 & delay & $a=8760$ & TICW & delay & $a=960$ \\
TSS(1-4) & Weibull & $\langle t\rangle=8.77 \times 10^{7}, \beta=1.2$ & TSSP(1-4)17PC & delay & $a=0.00025$ \\
TDC(1-4) & Weibull & $\langle t\rangle=4.38 \times 10^{8}, \beta=1$ & TSSP(1-4)33PC & uniform & $u=0.005$ \\
TRP(1-4) & Weibull & $\langle t\rangle=1.75 \times 10^{6}, \beta=1$ & TSSP(1-4)50PC & uniform & $u=0.009333$ \\
TSSPR(1-4) & Weibull & $\langle t\rangle=100000, \beta=1$ & TSSP(1-4)66PC & uniform & $u=0.009333$ \\
TIH1 & Weibull & $\langle t\rangle=6.35 \times 10^{7}, \beta=1.2$ & TSSP(1-4)83PC & uniform & $u=0.007778$ \\
TCC1 & Weibull & $\langle t\rangle=1.46 \times 10^{6}, \beta=1.5$ & TSSP(1-4)100PC & uniform & $u=7.0$ \\
TTP1 & Weibull & $\langle t\rangle=1.75 \times 10^{8}, \beta=1$ & TSSR(1-4)50PC & delay & $a=0.00025$ \\
TTP2 & Weibull & $\langle t\rangle=1.66 \times 10^{8}, \beta=1$ & TSSR(1-4)100PC & uniform & $u=0.325277$ \\
TTP3 & Weibull & $\langle t\rangle=1.00 \times 10^{8}, \beta=1$ & TOP117PC & delay & $a=0.00025$ \\
TTIV1 & Weibull & $\langle t\rangle=1.46 \times 10^{9}, \beta=1.1$ & TOP133PC & uniform & $u=0.005$ \\
TTIV2 & delay & $a=0.0003$ & TOP150PC & uniform & $u=0.009333$ \\
TTIS1 & uniform & $u=0.13$ & TOP166PC & uniform & $u=0.009333$ \\
TT1 & Weibull & $\langle t\rangle=1.00 \times 10^{6}, \beta=1.7$ & TOP183PC & uniform & $u=0.007778$ \\
TCD1 & Weibull & $\langle t\rangle=1.00 \times 10^{6}, \beta=1.2$ & TOP1100PC & uniform & $u=7.0$ \\
TMSS1 & delay & $a=4383$ & TAIVP117PC & delay & $a=0.00025$ \\
TVTR1 & delay & $a=43830$ & TAIVP133PC & uniform & $u=0.005$ \\
TFPMF(1,3,5) & Weibull & $\langle t\rangle=1.32 \times 10^{4}, \beta=1.2$ & TAIVP150PC & uniform & $u=0.009333$ \\
TFPMF(2,4,6) & delay & $a=24$ & TAIVP166PC & uniform & $u=0.009333$ \\
TFPEF(1,3,5) & Weibull & $\langle t\rangle=1.00 \times 10^{4}, \beta=1.2$ & TAIVP183PC & uniform & $u=0.007778$ \\
TFPEF(2,4,6) & delay & $a=24$ & TAIVP1100PC & uniform & $u=7.0$ \\
\hline
\end{tabular}

Table 2. Bond Graph concepts and single port elements used in this work. Note that the thermal domain is considered a psuedo-Bond Graph.

\begin{tabular}{llll}
\hline Concept & $\begin{array}{l}\text { Fluidic } \\
\text { Domain }\end{array}$ & $\begin{array}{l}\text { Thermal } \\
\text { Domain }\end{array}$ & Symbol \\
\hline Effort & Pressure & Temperature & $\mathbf{S}_{\mathbf{e}}$ \\
Flow & $\begin{array}{l}\text { Mass } \\
\text { flow rate }\end{array}$ & $\begin{array}{l}\text { Enthalpy } \\
\text { flow rate }\end{array}$ & $\mathbf{\mathbf { S } _ { \mathbf { f } }}$ \\
Resistance & $\begin{array}{l}\text { Pipe fluid } \\
\text { resistance }\end{array}$ & $\begin{array}{l}\text { Thermal } \\
\text { transfer } \\
\text { mechanism }\end{array}$ & $\mathbf{R}$ \\
& $\begin{array}{l}\text { Heat } \\
\text { capacity }\end{array}$ & $\mathbf{C}$ \\
\hline
\end{tabular}

dual domain capacitor represents stored volumes of coolant. Therefore, it acts as a capacitor in both domains, modeling the pressure of contained fluid, and varying its thermal capacitance in accordance with the coolant mass held.

\subsubsection{Equations for pipe resistor element}

The behavior of the pipe resistor is governed by,

$$
R_{\mathrm{f}}=\frac{\Delta p}{\dot{m}}=\frac{8 \mu l_{P}}{\pi r_{P}^{4} \rho_{\text {in }}} .
$$

(Nakayama 2013) where $l_{P}$ and $r_{P}$ are respectively the length $(10 \mathrm{~m})$ and radius of the pipe $(0.24 \mathrm{~m}), \mu$ is the dynamic viscosity of the fluid $\left(8.90 \times 10^{-4} \mathrm{~Pa} \cdot \mathrm{s}\right)$, and $\rho_{\text {in }}$ is the coolant density in the tank from which it flows. $\Delta p$ and $\dot{m}$ are respectively the pressure differential over the pipe and the mass flow through it, these being effort and flow variables of the element, with $R_{f}$ being the resulting, fluidic resistance. On the Bond Graph, pipe resistors elements are given the symbol, $\rightarrow \mathbf{R}_{\mathbf{P}}$.

\subsubsection{Equations for heat transfer transformer}

The transfer of thermal energy by advection in the transformer element coupled with a pipe resistor is given by,

$$
\begin{aligned}
\dot{H}_{\text {in }} & =T_{\text {in }} c_{p} \dot{m}, \\
\dot{H}_{\text {in }} T_{\text {in }} & =\dot{H}_{\text {out }} T_{\text {out }},
\end{aligned}
$$


where $c_{p}$ is the specific heat capacity of the coolant $\left(4.182 \times 10^{3} \mathrm{~J} \cdot(\mathrm{kg} \cdot \mathrm{K})^{-1}\right)$ and $\dot{m}$ is mass flow transferred by the pipe resulting from equation (1). The 'in' subscript indicates the inwards port of the element, and the 'out' subscript indicates the resulting values on the outward port. $T$ and $\dot{H}$ are respectively, temperature and enthalpy flow with the aforementioned subscripts applied as relevant in equation (2). The symbol marking a heat transfer transformer is $\rightarrow \mathbf{T F}_{\mathbf{H}} \rightarrow$.

\subsubsection{Equations for dual-domain capacitor element}

The fluidic variables, mass flow, $\dot{m}$ and pressure, $P$, and their respective counterparts in the thermal domain, enthalpy flow, $\dot{H}$, and temperature, $T$, are governed by equation (3). The form of equations (3a) to (3d) are unaltering:

$$
\begin{aligned}
V & =\frac{m}{\rho}, \\
h & =\frac{m}{\rho A_{T}}, \\
F_{t} & =\left[1+\beta\left(T-T_{\text {ref }}\right)\right]^{-1}, \\
F_{c} & =E\left(1-\rho_{\text {ref }} F_{t} \rho^{-1}\right) .
\end{aligned}
$$

To limit the volume of the fluid in the tank, two governing equations are conditional, such that,

$$
\begin{aligned}
& \text { for } m<V_{T} \rho_{\mathrm{ref}} F_{t}:\left\{\begin{array}{l}
\rho=\rho_{\mathrm{ref}} F_{t} \\
P=\rho g(h+a)
\end{array},\right. \\
& \text { for } m \geq V_{T} \rho_{\mathrm{ref}} F_{t}:\left\{\begin{array}{l}
\rho=m V^{-1} \\
P=\rho g(h+a)+F_{c},
\end{array}\right.
\end{aligned}
$$

where $V$ and $m$ are respectively the volume and mass of fluid in the tank, $\rho$ is the density of the coolant, $h$ is the level of the fluid relative the bottom of the tank, $A_{T}$ is the cross-sectional area of the tank in the horizontal plane $\left(14.1 \mathrm{~m}^{3}\right), F_{t}$ is used to calculated thermal expansion, for a cubic thermal expansion coefficient, $\beta\left(2.07 \mathrm{~K}^{-1}\right)$, with reference temperature, $T_{\text {ref }}(277.15 \mathrm{~K})$, and reference density, $\rho_{\text {ref }}\left(1000 \mathrm{~kg} \cdot \mathrm{m}^{-3}\right), F_{c}$ is the additional pressure resulting from compress for a given bulk modulus, $E, V_{T}\left(42.3 \mathrm{~m}^{3}\right)$, is the volume of the tank, and $g\left(9.81 \mathrm{~N} \cdot \mathrm{kg}^{-1}\right)$ is the local gravitational field strength.

Internally, the two energy domains are coupled via the specific heat capacity, such that,

$$
H=m c_{p} T .
$$

On the Bond Graph, the tank element is given the symbol, $\rightarrow \mathbf{C}_{\mathbf{T}}\llcorner$.

\subsection{Core temperature model}

The pseudo-Bond Graph model of the thermofluid dynamics of core coolant throughput is seen in figure 4. Heat transfer between the cladding and the core coolant is governed by the total thermal resistance, $R_{\mathrm{thm}}$,

$$
R_{\mathrm{thm}}=\left(\frac{1}{R_{\mathrm{thc}}}+\frac{1}{R_{\mathrm{rad}}}+\frac{1}{R_{\mathrm{cnv}}}\right)^{-1},
$$

where $R_{\text {thc }}, R_{\text {rad }}$, and $R_{\text {cnv }}$ are the contributions from thermal contact transfer, radiation, and forced convection respectively, such that,

$$
R_{\mathrm{thc}}=\frac{1}{2 \pi l r_{1}}\left(\frac{r_{1}}{k_{1}}+\frac{r_{2}-r_{1}}{k_{2}}\right),
$$

(Holman, 1990) where $r_{1}$ is the radius of outer fuel rod including cladding $(0.005 \mathrm{~m}), r_{2}$ is the inter radius of a fuel assembly pressure tube $(0.1 \mathrm{~m})$, $A_{x}$ is the rod surface area in contact with coolant ( $848 \mathrm{~m}^{3}$ for $4503 \mathrm{~m}$ long fuel rods), and $k_{1}$ and $k_{2}$ are respectively the thermal conductivities of the cladding $\left(14.19 \mathrm{~W} \cdot(\mathrm{m} \cdot \mathrm{K})^{-1}\right.$ Whitmarsh (1962) ) and coolant $\left(0.68 \mathrm{~W} \cdot(\mathrm{m} \cdot \mathrm{K})^{-1}\right.$ Incropera and de Witt (1990)),

$$
R_{\mathrm{rad}}=\left[\varepsilon \sigma A_{x}\left(T_{1}+T_{2}\right)\left(T_{1}^{2}+T_{2}^{2}\right)\right]^{-1},
$$

(Çengel and Boles, 2002) where $\varepsilon$ is the radiating surface's emissivity, $\sigma$ is the Stefan-Boltzmann constant, and $T_{1}$ and $T_{2}$ are respectively the temperatures of the fuel cladding and the core coolant (thus, $R_{\text {thm }}$ is not constant over the course of a

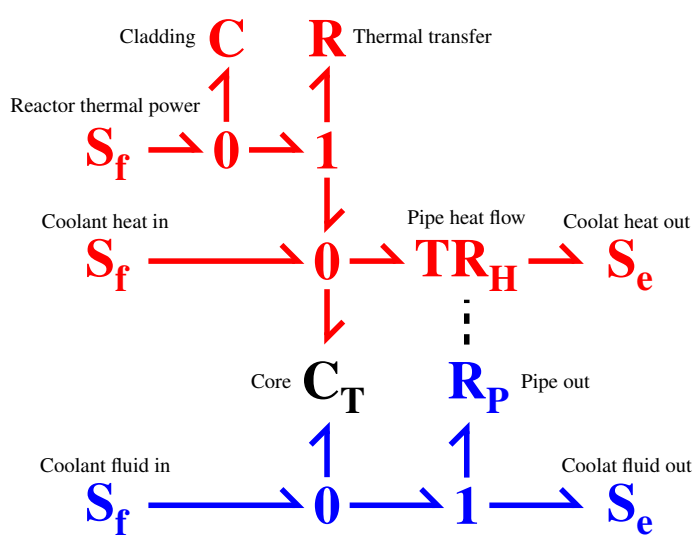

Fig. 4. Coupled-dual energy domain pseudo-Bond Graph structure for core coolant and cladding. The thermal domain is rendered in red and the fluidic domain is rendered in blue, with multi-domain elements rendered in black. Dashed lines represent the coupling between fluidic pipe resistors $\left(\mathbf{R}_{\mathbf{P}}\right)$ and thermal transfer transformers $\left(\mathbf{T R}_{\mathbf{H}}\right)$. The element's governing formulae are found in equations 11 to 8 . 
simulation), and

$$
R_{\mathrm{cnv}}=\frac{1}{h_{c} A_{x}},
$$

(Holman, 1990) where $h_{c}$ is the convection heat transfer coefficient (taken to be $5 \times 10^{4} \mathrm{~W} \cdot\left(\mathrm{m}^{2} \cdot \mathrm{K}\right)^{-1}$ for force convection of water in a pipe (Whitelaw, 2011)).

At full power, the reactor produces $9.2 \times 10^{8} \mathrm{~W}$ in heat, on shutdown its output is cut to $6 \%$. From that point, core decay heat output falls exponentially, reaching $1.5 \%$ at one hour after shutdown. Thus enthalpy entering the Bond Graph system from nuclear processes, $\dot{H}_{\mathrm{N}}$, at time, $t$, is given by,

$$
\begin{aligned}
& \dot{H}_{\mathrm{N}}= \\
& \begin{cases}\dot{H}_{\text {full }} & \text { for } t<t_{\mathrm{SI}} \\
0.06 \dot{H}_{\text {full }} \exp \left(\lambda\left[t_{\mathrm{SI}}-t\right]\right) & \text { for } t \geq t_{\mathrm{SI}}\end{cases}
\end{aligned}
$$

where $\dot{H}_{\text {full }}$ is full reactor output, $t_{\mathrm{SI}}$ is the time at which shutdown is initiated, and $\lambda$ is a constant equal to $(\ln (4) / 3600) \mathrm{s}^{-1}$.

The coolant heat in is the product of the mass flow into the core $\dot{m}_{\mathrm{CIn}}$, the specific heat capacity of the coolant, and its temperature, $T_{\mathrm{CIn}}$, such that,

$$
\dot{H}_{\mathrm{CIn}}=T_{\mathrm{CIn}} c_{p} \dot{m}_{\mathrm{CIn}} .
$$

The heat of the coolant flowing out of the system is the temperature of coolant in the core. The outgoing pressure, $P_{\mathrm{COut}}$, is,

$$
P_{\text {COut }}=P_{\mathrm{A}}-P_{\text {core }},
$$

where $P_{\mathrm{A}}$ and $P_{\text {core }}$ are respectively atmospheric pressure $(101325 \mathrm{~Pa})$ and the pressure of coolant in the core.

The cladding has a thermal heat capacity of $2.44 \times 10^{5} \mathrm{~J} \cdot \mathrm{K}^{-1}$ based on a total mass and specific heat capacity of $697 \mathrm{~kg}$ and $347 \mathrm{~J} \cdot(\mathrm{kg} \cdot \mathrm{K})^{-1}$ respectively, with an emissivity of 0.433 (Whitmarsh, 1962, Murphy and Havelock, 1976).

\subsection{Results in isolation}

Before combining the Bond Graph with the Petri Net, two simulations were conducted to observe its behavior running alone. In the first, the initial temperatures core coolant and cladding were $303 \mathrm{~K}$ and the model ran until equilibrium was reached, settling at $500 \mathrm{~K}$ for the core coolant, and $933 \mathrm{~K}$ for the cladding. In the second, a 2.25 hour long execution of the Bond Graph was conducted, with the initial temperatures at equilibrium. At 0.25 hours into the simulation, core shutdown was initiated, and the extraction of decay heat was observed. The results are shown in figure 5 , two hours after shutdown, the cladding and core

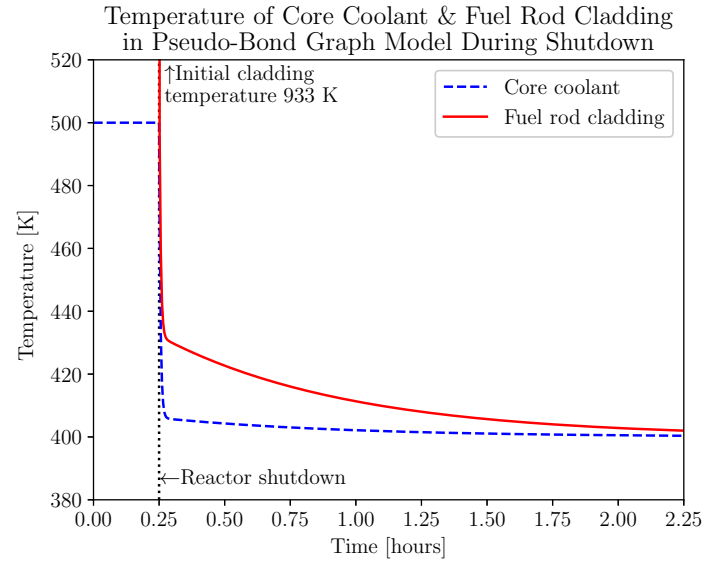

Fig. 5. Bond Graph simulation of reactor core coolant and cladding temperatures, commencing at full power and entering a shutdown state at 0.25 hours, after which core decay heat removal continues for two hours.

coolant have cooled to be close to the temperature of incoming coolant. In both simulations, a constant coolant inflow rate of $2200 \mathrm{~kg} \cdot \mathrm{s}^{-1}$ was used throughout.

\section{Hybrid Petri Net-Bond Graph}

\subsection{Interaction between models}

To control the Bond Graph, one must consider the physical consequences of faults in the Petri Net, and what physical consequences arising in the Bond Graph constitute a failure. To this end we extend the Petri Net to produce a severity of break associated with coolant circulation faults, with the resulting information transmitted to the Bond Graph. Likewise, the Petri Net structure is also extended such that places exist to deposit tokens when the Bond Graph enters a state that requires action in the Petri Net. A diagram illustrating these additions and their relationship to the Bond Graph is found in figure 6, where one will see the reduction of coolant throughput resulting from ruptures or feed pump failure, such that the incoming coolant mass flow, $\dot{m}_{\mathrm{CIn}}$, is,

$$
\begin{aligned}
& \dot{m}_{\mathrm{CIn}}= \\
& \left(\frac{1}{4} \sum_{i=1}^{4}\left(1-d_{\mathrm{SS}, i}\right)\right)\left(1-d_{\mathrm{OP}}\right)\left(1-v_{\mathrm{ti}} d_{\mathrm{TP}}\right) p \dot{m}_{\mathrm{full}},
\end{aligned}
$$

where $\dot{m}_{\text {full }}$ is the full operational coolant throughput $\left(2200 \mathrm{~kg} \cdot \mathrm{s}^{-1}\right), v_{\mathrm{ti}}$ is the state of the turbine isolation valve, taking the value 1 when open, and 0 when shut. $p$ is the status of the feed pumps, taking the value of 1 if at least two are available, 


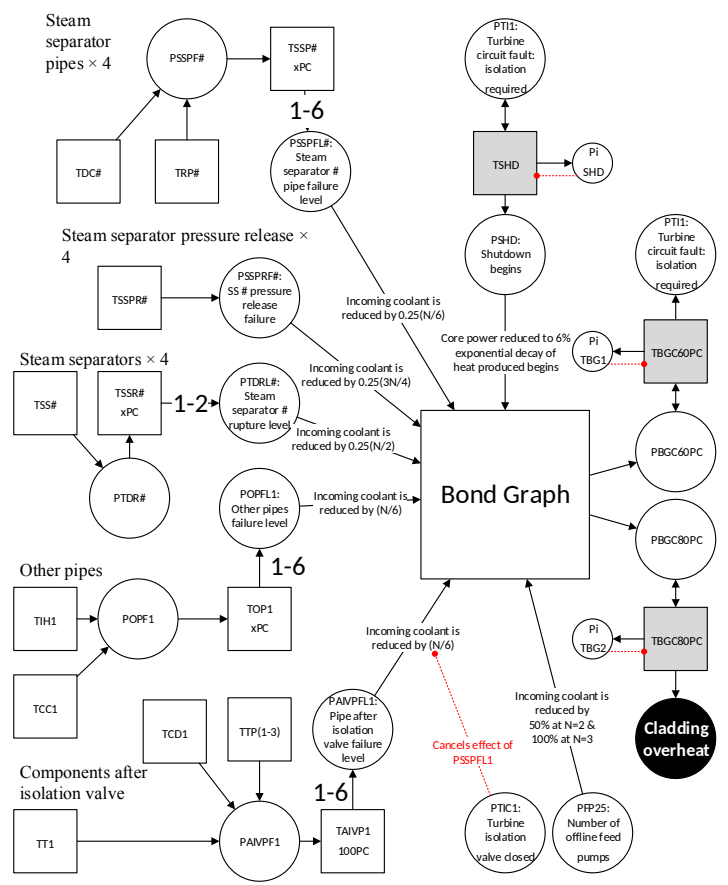

Fig. 6. Interactions Petri Net (extended from figure 3) and Bond Graph (figure 4 models of reactor coolant circulation. " $\mathrm{x}$ " is a failure severity placeholder, see table 1 for details.

0.5 if only one pump is functional, and 0 is all pumps have failed, and $d_{\mathrm{SS}, i}, d_{\mathrm{OP}}$, and $d_{\mathrm{TP}}$ are damaged factors for the steam separators, other piping (inlet header, coolant channels, and first section of pipe to turbine), and piping beyond the turbine isolation valve (the latter two sections of the turbine pipe, the turbine itself, and the condenser), respectively, and all of which represent the coolant lost to a breach, taking a value between 0 (no rupture) and 1 (complete loss of coolant circulation through component). If the cladding's temperature reaches $60 \%$ of its melting point, $2122 \mathrm{~K}$ (Whitmarsh 1962), a shutdown command is given, and at $80 \%$, the simulation terminates on the presumption that the reactor will imminently sustain damage as a result of the extreme temperature.

\subsection{Hybrid model results}

5000 executions of the joint Petri Net-Bond Graph model were conducted. When simulations encountered a problem, the vast majority were able to retain control the core temperature by going to shutdown. However, in some cases, the coolant fault that emerged was too severe and the simulation ended with the core coolant and cladding at elevated temperatures, with one instance of termination resulting from the cladding temperature surpassing the $60 \%$ of melting temperature threshold. In figure 7, a histogram is plotted show-

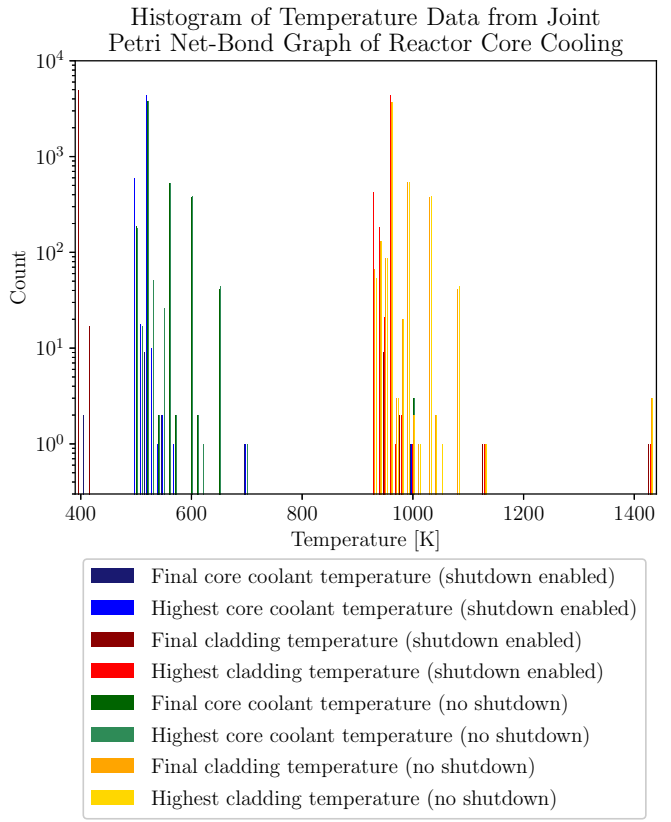

Fig. 7. Histograms depicting the distribution of temperatures found in the joint Petri Net-Bond Graph model, with and without reactor shutdown enabled. Bars width is $10 \mathrm{~K}$.

ing the distribution of core coolant and cladding temperatures, both at the end of a simulation and the highest intermediate values reached. When temperatures rise above the normal operating values, the increase is generally small, with the highest core coolant temperature of 4402 simulations falling into the 505 to $555 \mathrm{~K}$ range, and the highest cladding temperature of 4572 simulations being within 935 to $975 \mathrm{~K}$.

As few simulations ended in a fault, a second set of 5000 simulations was conducted. In this set, the ability to close the isolate valve and shutdown the reactor was removed, and therefore these results can be considered a deeper exploration of the subset of systems encountering such a fault. The distribution of final and highest intermediate temperatures reached for these results is shown in figure 7. Unsurprising, more simulations are seen to get significantly hot when the reactor shutdown procedure is eliminated, although only three instances are seen in which the cladding temperature passes the $60 \%$ threshold. In exactly 1000 simulations, the highest temperature reached by both the core coolant and cladding was $50 \mathrm{~K}$ above prefault levels, with 440 simulations experiencing increases of $100 \mathrm{~K}$.

\section{Discussion}

The Petri Net constructed in this work has given an estimation of the frequency of faults requiring activation of emergency core coolant injection. A 
subset of which of these would experience further faults, leading to a loss of coolant event. Our continuing work will model the sequence that follows an initiating event, using the data produced in this work to calculated overall failure frequency, and consideration of each the major reactor subsystems will be given before a whole system depiction is constructed. A joint Petri Net-Bond Graph model was presented for the demonstration system, in which one observes the range of temperatures reached by core coolant and cladding during the occurrence of faults. In these simulations, elevated cladding temperatures were seen, but no instances in which melting would be imminent arose. Where applicable, we will continue to couple our Petri Nets with a Bond Graph representation of system thermodynamics as the scope of our studies expands. It is apparent that a greater volume of simulations need be conducted to capture the full spectrum of outcomes.

\section{Acknowledgments}

Gratitude is expressed to EPSRC for their financial support of the DaMSSLE project, reference code EP/M018210/1. Additional thanks go to Andrey Vasilyev for useful conversations regarding the Modelica modelling language and the BondLib package.

\section{References}

Andrews, J. D. and T. R. Moss (1993). Risk and Reliability Assessment. Longman.

Barringer \& Associates, Inc (Last edited: 2010). Weibull Reliability Database For Failure Data For Various Components. http://www. barringer1.com/wdbase.htm/Accessed November 2018.

Cadwallader, L. C. (1998). Selected Component Faiure Rate Values From Fusion Safety Assessment Tasks. Idaho National Engineering and Environmental Laboratory INEEL/EXT-9800892 .

Çengel, Y. A. and M. A. Boles (2002). Thermodynamics: An Engineering Approach $\left(2015,8^{\text {th }}\right.$ in SI Units ed.). McGraw-Hill Education.

Cellier, F. E. and Àngela Nebot (2005). The Modelica Bond Graph Library. In Proceedings of the $4^{\text {th }}$ International Modelica Conference, Hamburg, pp. 57-65.

Eide, S. and M. Calley (1993). Generic component failure database. Proceedings of PSA international topical meeting pp 1175, vol 2 .

Eide, S., S. Chmielewski, and T. Swantz (1990). Generic Component Failure Data Base for Light Water and Liquid Sodium Reactor PRAs. Idaho National Engineering Laboratory.

Fritzson, P. and V. Engelson (1998). Modelica - A unified object-oriented language for system modeling and simulation. Jul E. (eds)
ECOOP'98 - Object-Oriented Programming. ECOOP 1998. Lecture Notes in Computer Science 1445.

GRS (1990). German Risk Study Nuclear Power Plants Phase B GRS-74. Technical report, Gesellschaft für Reaktorsicherheit $\mathrm{mbH}$.

Holman, J. P. (1990). Heat Transfer $\left(2010,10^{\text {th }}\right.$ ed.). McGraw-Hill Higher Education.

Hubble, W. H. and C. F. Miller (1976-1978). Data Summaries of Licensee Event Reports of Valves at U.S. Commercial Nuclear Power Plants NUREG/CR -1363. Technical report, Office of Nuclear Regulatory Reseach.

IAEA (1988). IAEA-TECDOC-478 Component Reliability Data for Use in Probabilistic Safety Assessment. Technical report, Internation Atomic Energy Agency.

IAEA (Last editted: 2019). PRIS - Miscellaneous reports - Operational by Age. WWW.iaea. org/PRIS/WorldStatistics/ OperationalByAge.aspx Accessed Februrary 2019.

Incropera, F. P. and D. P. de Witt (1990). Fundamentals of Heat and Mass Transfer. Wiley.

Karnopp, D. (1978). Pseudo Bond Graphs for Thermal Energy Transport. Journal of Dynamic Systems, Measurement, and Control 100, 165169.

Modelon AB. (Version 2.4, 2018). JModelica. https: / / jmodelica.org.

Murphy, E. and F. Havelock (1976). Emissivity of zirconium alloys in air in the temperature range $100-400^{\circ} \mathrm{c}$. Journal of Nuclear Materials 60(2), 167-176.

Nakayama, Y. (2013). Introduction to fluid mechanics (2018， $2^{\text {nd }}$ ed.). ButterworthHeinemann.

Paynter, H. M. (1961). Analysis and Design of Engineering Systems. The M.I.T. Press.

Petri, C. A. (1962). Kommunikation mit Automaten (In German). Ph. D. thesis, Technical University Darmstadt.

Rasmussen, N. C. (1975). Reactor safety study: An assessment of accident risks in US commercial nuclear power plants. US Nuclear Regulatory Commission.

Smith, D. J. (1981). Reliability, Maintainability and Risk. Practical Methods for Engineers including Reliability Centred Maintenance and Safety-Related Systems (2005, $7^{\text {th }}$ ed.). Elsevier Butterworth-Heinemann.

Whitelaw, J. H. $\quad$ Last edited: 2011). CONVECTIVE HEAT TRANSFER. http://thermopedia.com/es/ content /660/Accessed February 2018.

Whitmarsh, C. L. (1962). Review of Zircaloy2 and Zircaloy-4 Properties Relevant to N.S. Savannah Reactor Design ornl-3281 uc-80 - reactor technology tid-4500 (17th ed.). Technical report, Oak Ridge National Laboratory. 